\title{
ENSINO DE HISTÓRIA, DIVERSIDADE CULTURAL E LEI 10.639/03
}

Acácia Regina Pereira ${ }^{\mathrm{i}}$

\begin{abstract}
Resumo: O presente artigo apresenta reflexões acerca do ensino e aprendizado de História frente às demandas sociais, tais como as instituídas pela Lei 10.639/03, além de focar na problematização do respeito à diversidade cultural durante as aulas de História em turmas do $6^{\circ}$ ano do fundamental. Observa como os alunos lidam com os conteúdos históricos ensinados e evidencia que o currículo neste ano de escolaridade visa ao estudo das civilizações antigas, a vida material desses povos e suas crenças. Ocorre um enfoque nas apropriações dos alunos sobre o conhecimento histórico e quais relações têm sido estabelecidas com as suas experiências cotidianas, a partir de registros em diários de campo e entrevistas feitas pelos bolsistas do Subprojeto História do PIBID, da Faculdade de Formação de Professores/UERJ, realizado em um colégio estadual em São Gonçalo.
\end{abstract}

Palavras-chave: Ensino de História, Diversidade Cultural, PIBID.

\section{HISTORY TEACHING, CULTURAL DIVERSITY AND LAW 10.639/03}

\begin{abstract}
This article aims to present reflections about teaching and learning across history to social demands, such as those established by Law 10.639 / 03. In addition to focusing on the critical respect for cultural diversity during history lessons in classes of the 6th grade of elementary, watching these students deal with taught historical contents, showing that the curriculum in this series aims to study ancient civilizations, the life material of these people and their beliefs. There is a focus on appropriations of students on historical knowledge and relationships which have been established with their everyday experiences, from records in field diaries and interviews made by fellows Activity History PIBID, Faculty of Teacher Education / UERJ, held in a state school in São Gonçalo.
\end{abstract}

Keywords: History Teaching, Cultural diversity, PIBID.

\section{Introdução}

O presente artigo visa trabalhar a temática da Diversidade Cultural e as suas implicações no ensino de História. Diversas mudanças ocorreram no Ensino de História como, por exemplo, a promulgação da Lei Federal 10.639/03, que tornou obrigatório o ensino da história e cultura afro-brasileira e africana em todas as escolas públicas e privadas, do Ensino Fundamental ao Ensino Médio, conteúdo esse que deve ser ministrado no âmbito de todo o currículo escolar, em especial nas áreas de Artes, Literatura e História. E a Lei 11.645/08, a qual altera a lei mencionada acima e obriga também o estudo da História dos 
povos indígenas no currículo escolar da Educação Básica. Estas Leis que são consideradas instrumentos importantes de combate ao racismo no Brasil, como destaca Alberti (2013). Apesar da lei 11.645/08 ser importante no que tange à temática da diversidade cultural, para o presente ensaio, não será utilizada, uma vez que os aportes trazidos por ela não têm rebatimento direto nos conteúdos do sexto ano.

Essas leis, ao modificarem a Lei de Diretrizes e Bases da Educação (LDB), se configuram em grandes aliadas no debate sobre diversidade para a construção de uma educação plural e igualitária. A importância desse debate nas escolas se dá pelo fato da sociedade brasileira ser formada não só por diferentes etnias, mas também por imigrantes de diferentes países, o que nos coloca em contato com grupos diferenciados. É possível perceber que, muitas vezes, esse contato com grupos diferenciados nos planos sociais e culturais é marcado pelo preconceito e pela discriminação.

No entanto, o grande problema em torno dessa lei é que se passou aproximadamente 11 anos da sua promulgação, e o ensino da História e cultura afro-brasileira e africana, inúmeras vezes, é apresentado ao aluno carregado de estereótipos e/ou o(a) professor(a) encontra inúmeras dificuldades em passar esse conteúdo. Essas dificuldades aparecem na estrutura eurocêntrica encontrada no currículo e no cotidiano escolar de diversas escolas, falta de disciplinas obrigatórias de História da África na formação dos professores durante sua graduação, além da maioria dos livros didáticos de História, entre outras disciplinas, não reservarem para o conteúdo sobre África espaço adequado. Com isso, os alunos passam a construir apenas estereótipos sobre a África e sua população.

Este trabalho está inserido na dinâmica de pesquisa do Programa de Iniciação à Docência (PIBID), pelo projeto História, no subprojeto intitulado "As estratégias didáticas na aprendizagem do conhecimento histórico escolar", no qual, além de visar ao acompanhamento nas atividades in locus pelos(as) licenciandos(as), busca-se a proposição de atividades de ensino para as aulas de História.

Visto isso, importa salientar que a elaboração deste trabalho se deu a partir das observações feitas, principalmente, nas turmas de sexto ano de um colégio público situado em São Gonçalo (região metropolitana do Estado do Rio de Janeiro). Nessas observações, percebemos que muitos alunos possuem, de maneira inconsciente, certa intolerância ${ }^{\text {ii }}$ quanto a assuntos que versam sobre os costumes, modo de vida e crenças dos povos que não pertencem ao nosso período histórico. Para além, percebemos, através da matriz de pensamento 
europeia-ocidental predominante no Ensino de História, que esses alunos acabam tendo uma visão anacrônica da história, não conseguindo diferenciar determinados conteúdos, como a temática dos diferentes tipos de escravidão no decorrer da história, por exemplo.

A partir dessas questões, este artigo será dividido em três partes. De início, será realizada uma breve discussão sobre o currículo e suas variadas definições, assim como a sua importância para os debates ocorridos no cotidiano escolar. Em seguida, serão brevemente apresentadas as Leis 10.639/03 e 11.645/08 como ferramentas de reflexão para ampliarmos o debate sobre a diversidade cultural nos bancos escolares, mas é importante ressaltar que a Lei 10.639/03 terá maior destaque neste ensaio, pois será abordado como essa discussão rebate no ensino de História, apontando para as potencialidades que a disciplina tem para trabalhar determinados assuntos. Por último, serão analisados os registros construídos em relatos dos bolsistas e da professora supervisora que acompanha as turmas de sexto ano e também em diários de campo, feitos pelos licenciandos em História do PIBID, da Universidade do Estado do Rio de Janeiro (FFP), em especial os que acompanham as turmas de sexto ano do Ensino Fundamental.

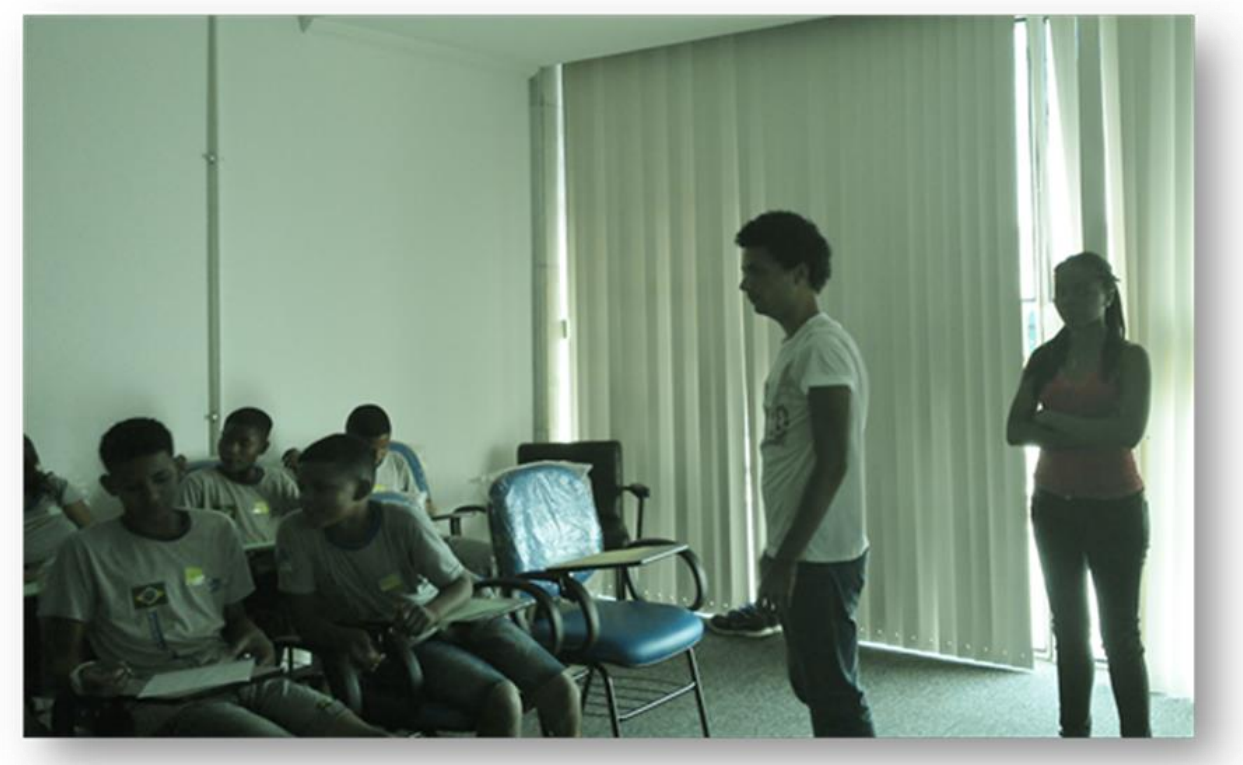

Figura 1- Bolsistas do Projeto PIBID/ História da Faculdade de Formação de Professores da Universidade do Estado do Rio de Janeiro, auxiliando durante atividade com os alunos da turma 603. Foto tirada no dia 13 de outubro de 2014. 


\section{Currículo e cotidiano escolar}

Antes de começarmos a discussão sobre a diversidade no ambiente escolar, pretendemos fazer uma breve discussão sobre o currículo. É importante salientar que, para além dos conteúdos ensinados, entendemos o currículo enquanto uma coalisão de perspectivas que estão presentes no cotidiano escolar. Dessa forma, assim como Tomaz Tadeu Silva (1999), entendemos que as questões culturais estão ligadas às questões históricas e de poder e que, ao analisá-las, não as devemos separar. Em complemento, Ivor Goodson (2007) nos mostra que o currículo pode ser entendido como resultado de diversos conflitos entre diferentes ideologias e atores sociais.

Nessa complexidade da discussão sobre o currículo, Kelly (1981) indica que podemos entendê-lo através de três eixos de análise, ou seja, o currículo pode ser dividido em: i) currículo oficial, ii) currículo real e iii) currículo oculto.

Sobre essa ideia, o autor desenvolve que o currículo oficial se configura naquele currículo que, na educação básica pública - nosso campo de análise -, vai ser construído pelo Estado e vai, através de inúmeros instrumentos (LDB, PNLD, PCN, entre outros), influenciar na construção dos livros didáticos, paradidáticos e na seleção de conteúdos e práticas que devem ser minimamente construídos no ambiente escolar. No caso do estado do Rio de Janeiro, temos o Currículo Mínimo iii.

Em relação ao currículo real, o autor destaca como sendo aquele que é praticado pelos professores em seu cotidiano escolar. Já o currículo oculto é aquele que está presente no ambiente escolar, mas não pode ser observado de maneira nítida pelos alunos e/ou demais membros do cotidiano escolar. Dessa forma, o autor indica que:

[...] alguns educadores falam sobre o currículo oculto pelo que entendem aquelas coisas que os alunos aprendem na escola por causa do modo pelo qual o trabalho da escola é planejado e organizado, mas que não são em si mesmas incluídas no planejamento [...] (KELLY, 1981, p. 4).

Por sua vez, Silva (1999) indica que são várias as fontes que podem construir o currículo oculto, desde relações sociais (professor-aluno, aluno-funcionários, alunos-alunos) 
até a própria organização do espaço escolar (organização da sala de aula, disposição das salas) e do tempo escolar (um tempo para cada tarefa, para cada disciplina, etc.). Todos esses fatores vão ensinar coisas diferentes para os indivíduos, e isso está intrinsicamente ligado ao currículo oculto, ao que está sendo ensinado, uma vez que:

O currículo oculto ensina, ainda, através de rituais, regras, regulamentos, normas. Aprende-se também através das diversas divisões e categorizações explícitas ou implícitas próprias da experiência escolar: entre os mais "capazes" e os menos "capazes", entre meninos e meninas, entre um currículo acadêmico e um currículo profissional. (SILVA, 1999, p. 79).

Esse currículo oculto é responsável, em grande parte, pela transmissão de valores que vão ajudar a formar as diferentes concepções/visões de mundo no que tange às relações raciais, sociais, espirituais, de gênero, dentre outras. Entretanto, Kelly (1981) ainda nos mostra que alguns desses valores que consideramos ocultos no currículo estão "expostos" nos pensamentos dos profissionais que organizam e praticam o currículo, ou seja, o currículo passa a ser oculto para o sujeito que o recebe (aluno), mas não para o que o pratica/aplica (professores, coordenadores, direção).

Para o presente trabalho, entender a diferença entre currículo prescrito (currículo oficial), currículo praticado (currículo real) e currículo oculto é de suma importância, uma vez que esses conceitos nos possibilitam evidenciar a necessidade de uma prática que eduque para a diversidade.

Partindo de uma análise ampla sobre o que os meios acadêmicos entendem por currículo no Brasil, Macedo (2006) mostra que a separação entre o entendimento do currículo enquanto criação (prescrição) e enquanto ação (prática) faz com que, hegemonicamente, entendamos o currículo somente como aquele currículo prescrito, dando a esse o nome e entendimento de currículo. É essa dicotomia que faz com que esse currículo assuma concepções verticais e hierárquicas no que tange às relações de poder e de saber.

Através da análise sobre currículo oficial, vemos que este representa a tentativa de manter as relações de poder em nossa sociedade, ou seja, na sua construção - saberes, culturas e formas de relação da sociedade - são hierarquizados, subalternizados e excluídos de acordo com os pensamentos das classes dominantes, sendo estes os pensamentos hegemônicos no ambiente escolar. 
Nesse panorama, Candau (2007) enfatiza que as questões entorno do currículo têm sido um alvo recorrente de autoridades, professores, gestores, pais, estudantes e, no decorrer da discussão, a autora destaca que essas cobranças em torno do currículo se dão devido à importância dele no processo educativo escolar. Candau (2007) ressalta isso ao evidenciar que:

O currículo é, em outras palavras, o coração da escola, o espaço central em que todos atuamos, o que nos torna, nos diferentes níveis do processo educacional, responsáveis por sua elaboração. O papel do educador no processo curricular é, assim, fundamental. Ele é um dos grandes artífices, queira ou não, da construção dos currículos que se materializam nas escolas e nas salas de aula. (CANDAU, 2007 p. 19).

A partir daí podemos observar o porquê da preocupação corrente com o currículo. E trazer também para nós a responsabilidade de colaborar com a elaboração de um currículo mais atraente e democrático. Ao nos referir à elaboração de um currículo mais democrático, nos referimos à superação de um currículo marcado pela visão eurocêntrica e excludente. Essa crítica vem da necessidade de entendermos que o colonialismo foi, para além de um sistema de dominação política e econômica, um processo de dominação cultural. Contudo,

Apesar da influência marcante da cultura de matriz européia por força da colonização ibérica em nosso país, a cultura tida como dominante não conseguiu, de todo, apagar as culturas indígena e africana. Muito pelo contrário, o colonizador europeu deixou-se influenciar pela riqueza da pluralidade cultural de índios e negros. No entanto, o modelo de organização implantado pelos portugueses também se fez presente no campo da educação e da cultura. (FERNANDES, 2005, p. 379).

Nesse panorama, entendemos não só os conteúdos, mas o currículo em sua totalidade, enquanto um campo em disputa, sendo o currículo praticado o lócus para o início da criação de uma educação antirracista. Assim, se faz necessário entender de maneira mais aprofundada como o debate sobre a diversidade cultural aparece no ensino de História e os mecanismos que nos auxiliam para um ensino libertador.

\section{Diversidade cultural e o ensino de História}


Esse debate tem um rebatimento muito forte dentro do ensino de História, uma vez que essa disciplina é, por excelência, aquela que deve tratar sobre as diferentes civilizações e, consequentemente, vai tratar sobre as diferentes culturas. Nesse sentido, um ensino de História que possibilite ao estudante não criar hierarquizações e preconceitos contra as outras culturas é necessário.

Alberti (2013) afirma que a partir de 1930 com a narrativa da identidade nacional ganha força o caráter multiétnico da nossa sociedade e que os problemas sociais e injustiças derivam da herança da escravidão, e não do racismo propriamente dito, ou seja, essa narrativa torna evidente que somos uma sociedade miscigenada formada por brancos, negros e indígenas que se misturaram para dar origem ao "brasileiro", de modo que nossos problemas sociais não devem ser confundidos com o Racismo.

Essa omissão do Racismo se manteve e atingiu o ensino. Podemos ver isso na dificuldade encontrada quando o educador tenta colocar em prática o ensino de História e cultura afro-brasileira e/ou indígena. Segundo Fonseca (2003), a nova Lei de Diretrizes e Bases da Educação Nacional (LDB) responde a várias de nossas indagações e debates sobre: o que é significativo, válido e importante de ser ensinado da História do Brasil e do Mundo? O que e como ensinar nas aulas de História? Para quê? Por quê?

$\mathrm{O}$ artigo 26, acrescentado à Lei $\mathrm{n}^{\circ}$ 9.394/96, possibilita mais do que a inclusão de novos conteúdos ao currículo do Ensino Fundamental e Médio; ele exige que sejam repensadas relações étnico-raciais, sociais, pedagógicas, procedimentos de ensino, condições oferecidas para a aprendizagem, objetivos táticos e explícitos da educação oferecida pelas escolas:

Art. $26^{\circ}$ - Os currículos do ensino fundamental e médio devem ter uma base nacional comum, a ser complementada, em cada sistema de ensino e estabelecimento escolar, por uma parte diversificada, exigida pelas características regionais e locais da sociedade, da cultura, da economia e da clientela.

$\S 4^{\circ}$ - O ensino da História do Brasil levará em conta as contribuições das diferentes culturas e etnias para a formação do povo brasileiro, especialmente das matrizes indígena, africana e europeia.

Art. $36^{\circ}$ - O currículo do ensino médio observará o disposto na Seção I deste Capítulo e as seguintes diretrizes:

I - destacará a educação tecnológica básica, a compreensão do significado da ciência, das letras e das artes; o processo histórico de transformação da sociedade e da cultura; a língua portuguesa como instrumento de comunicação, acesso ao conhecimento e exercício da cidadania; (LDB apud FONSECA, 2003). 
É caminhando nessa perspectiva que buscamos, neste momento, apresentar algumas possibilidades de discussão sobre a temática dentro do ensino de História para, no próximo momento, observar como essas temáticas foram recebidas pelos estudantes da escola acompanhada.

A fim de valorizar a diversidade e combater as desigualdades, alguns movimentos sociais intensificaram os debates e propostas políticas com a intenção de rechaçar a desigualdade propagada a séculos. Como exemplo, temos a Lei 10.639/03, que torna obrigatório o ensino de História e cultura africana e afro-brasileira em todas as escolas de Educação Básica brasileiras, e a Lei 11.645/08, que, junto a essa temática, inclui também a questão do indígena como conteúdo curricular obrigatório. Como dito anteriormente, essas Leis modificaram a Lei de Diretrizes e Bases da Educação Nacional - LDB 9.394/06, que define e regulariza o sistema de educação brasileiro com base nos princípios presentes na Constituição.

Segundo Lorene dos Santos (2013), a compreensão do que se passa, hoje, dentro de algumas escolas públicas brasileiras, ao introduzir esse novo componente curricular, nos exige levar em conta toda a complexidade da questão racial brasileira (p. 58), ou seja, só entenderemos o racismo na atualidade se conhecermos toda a trajetória da questão racial no Brasil. Porém, a discussão em torno da temática africana e afro-brasileira são negadas por parte da sociedade brasileira, por carregar um forte caráter político e social.

Como podemos observar, há a negação dessa temática também no Ensino de História. José Ricardo Oriá Fernandes (2005) destaca que os livros didáticos de História são permeados pela concepção positivista que evidencia o aparecimento dos "Heróis Nacionais", na sua maioria brancos, tirando o foco da participação de outros segmentos sociais no processo histórico nacional. O negro e o índio aparecem, na maioria das vezes, numa posição subalternizada em relação ao branco europeu. Um exemplo disso é quando se inicia os estudos sobre a História do Brasil com a chegada dos portugueses: onde é desprezada a presença dos índigenas, são exaltados os conquistadores portugueses pela "descoberta" desse território e são ocultados os genocídios contra as populações indígenas do Brasil. Já em relação aos africanos, estes são apresentados como objetos/mercadorias pelos seus proprietários. É ocultado, por exemplo, a participação do negro na construção da História e cultura brasileira. 
Essas questões levantadas nos levam a entender que o Racismo é um problema que envolve toda a sociedade e, principalmente, os educadores, como destaca Alberti (2013). Foi somente a partir dos debates dos movimentos sociais sobre essas temáticas e a implantação das Leis que passou a ser debatido, por alguns historiadores e pedagogos, como abordar tal tema dentro da sala de aula. Gabriel Jorge Quadros de Paula (2009) diz que tal dificuldade ocorre pelo fato da maioria dos alunos possuírem uma dificuldade de compreender diversos temas do cotidiano.

Alberti (2013) ressalta o ensino de questões consideradas sensíveis como imigração europeia, holocausto, racismo, escravidão, tráfico de escravos, religião como conteúdos muitas vezes evitados pelos educadores, envolvendo, nesse sentido, uma injustiça com os respectivos grupos sociais envolvidos.

Outro ponto que deve ser destacado é o modo folclorizado como, muitas vezes, essas culturas são apresentadas para os alunos. José Ricardo Oriá Fernandes (2005) destaca que: Quando se trata de abordar a cultura dessas minorias, ela é vista de forma folclorizada e pitoresca, como mero legado deixado por índios e negros, mas dando-se ao europeu a condição de portador de uma 'cultura superior e civilizada' (p. 380).

\section{Estudo de caso: turma de sexto ano}

O estudo de caso foi realizado no Colégio Estadual Dr. Adino Xavier, localizado em São Gonçalo, região metropolitana do Rio de Janeiro. Uma escola grande, que trabalha com turmas do Ensino Fundamental II ( $6^{\circ}$ ao $9^{\circ}$ ano), com o Ensino Médio ( $1^{\circ}$ ao $3^{\circ}$ ano $)$ e com o EJA (Educação de Jovens e Adultos). Escolhemos a referida turma de sexto ano por ser a única turma desta série que acompanhamos e por conta das observações anteriores que tivemos e nos impulsionaram a trabalhar esse tema.

O ponto de partida que me levou a pensar este trabalho foi a realização de uma atividade na qual o conteúdo a ser tratado com os alunos era o Egito Antigo. Nessa atividade, apresentamos o clipe do Michael Jackson "Remember to me", a fim de que os alunos compreendessem, a partir das imagens, algumas características daquela sociedade. Ao fim do clipe, foram reforçadas aos alunos essas características e, entre essas apresentações, foi perguntado aos alunos por que os participantes do clipe eram negros, e os alunos prontamente 
responderam coisas como: "Por que eles são escravos?", associando o negro a seres humanos escravizados. Também foi perguntado à professora o seguinte: "Professora, você é racista? Poxa, você fala negro toda hora", o que nos levou a perceber que os alunos não sabiam conceitos como racismo, preconceito, discriminação e que esses conceitos devem ser trabalhados com esses alunos desde as séries iniciais.

O colégio parceiro do Pibid, Subprojeto História, costuma mobilizar a equipe escolar com um projeto de leitura. No ano de 2014, o tema do projeto foi "Pluralidade Cultural", o qual tinha como proposta inicial que cada professor, independente do curso, trabalhasse o tema com suas turmas, motivo que impulsionou a realização deste trabalho.

Em sala de aula, buscamos observar o cotidiano dos alunos e professores, propor atividades para auxiliar os docentes, com a finalidade de compreender o cotidiano escolar para uma aproximação entre escola e universidade, de acordo com o objetivo do Programa Institucional de Bolsas de Iniciação à Docência (PIBID). Após conhecer o projeto de leitura, passou-se a ser observado como os alunos se comportavam em relação às diferentes culturas e sociedades.

Durante esse período de observação na turma 603, vimos que ela é formada por alunos que vieram de outras escolas municipais da região, já que a escola não tem turmas de $5^{\circ}$ ano do Ensino Fundamental I; além disso, compõem-na alunos repetentes da própria escola. A idade dos alunos da turma varia de 11 a 15 anos de idade, de acordo com as informações do Perfil do Adolescente e Jovem Fluminense ${ }^{\text {iv }}$. Veja o gráfico a seguir:

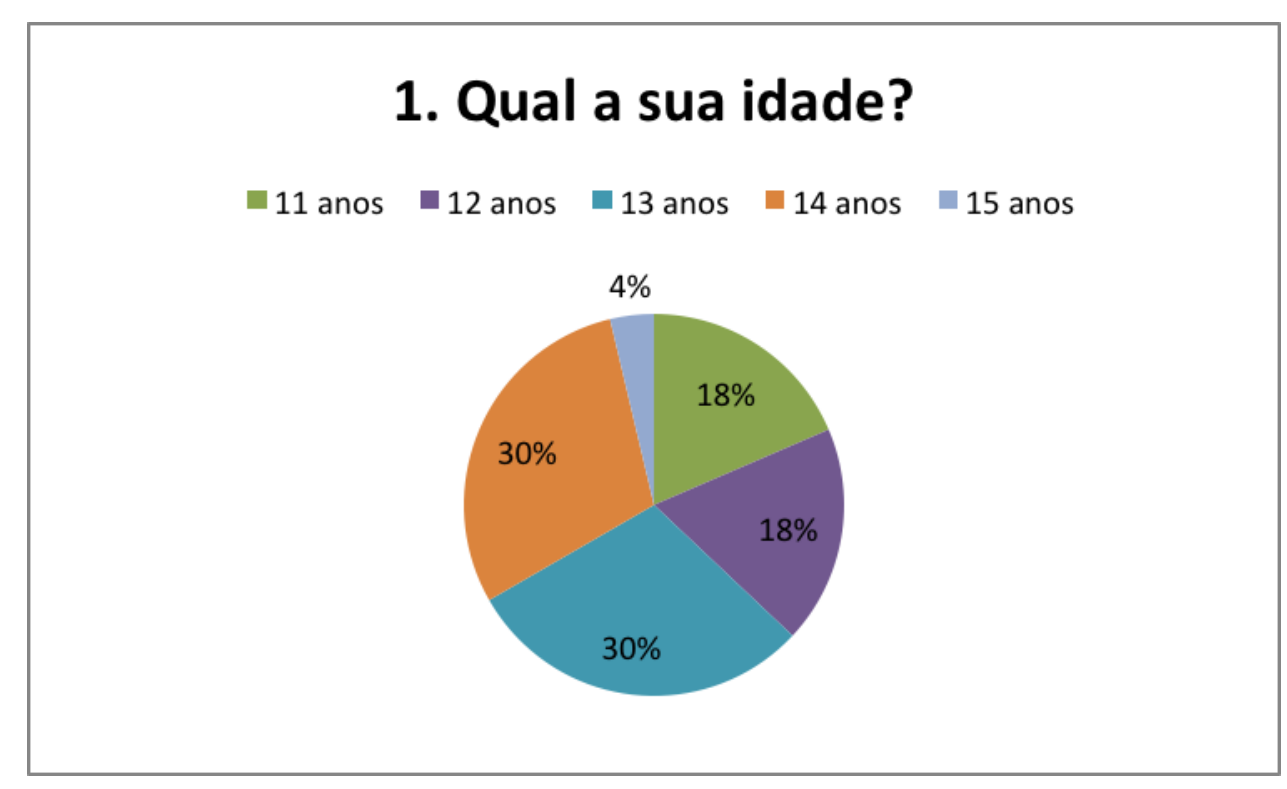


Equação 1 - Demonstra o percentual (\%) da idade dos alunos da turma 603 do colégio parceiro do projeto. Realizado pelos bolsistas do Subprojeto História da Faculdade de Formação de Professores da Universidade do Estado do Rio de Janeiro.

Além dessas observações, nós destacamos alguns casos que foram apresentados por alguns bolsistas, em especial os que acompanham as turmas de sexto ano e a professora supervisora, através de uma entrevista que tinha como objetivo o questionamento e levantamento de informações como, por exemplo, se os bolsistas têm conhecimento da Lei 10.639/03 e como é aplicada juntamente com a professora supervisora, promovendo a reflexão sobre uma educação antirracista, a partir das práticas pedagógicas.

Quando questionados se já chegaram a observar algum tipo de intolerância racial em sala de aula, pudemos observar que há certo distanciamento desses alunos com determinados temas como Egito Antigo, mais especificamente as religiões desse povo e as diferentes formas de escravidão, as mitologias gregas e romanas, entre outros assuntos, como podemos observar no depoimento a seguir:

[...] Como estamos trabalhando com história antiga, o conteúdo muito se distancia do mundo atual. Conforme religião, os costumes, e o modo de vida são bastantes distintos, os alunos acabam mostrando certa intolerância. (Depoimento 1) $)^{\mathrm{v}}$.

Foi enfatizado também que os comportamentos considerados preconceituosos não estão diretamente relacionados com os conteúdos ministrados, mesmo sendo observada uma maior incidência quando os assuntos fogem da lógica eurocêntrica ocidental moderna. É importante ressaltar que, em alguns casos, os próprios alunos acabam reproduzindo uma série de estigmas discriminatórios. Contudo, essas ofensas acabam sendo naturalizadas na forma de "brincadeiras", e o próprio aluno que foi "alvo" de discriminação não consegue enxergar aquilo como tal. Essas são questões nítidas no cotidiano escolar, como afirma uma outra bolsista do PIBID:

(...) Posso dizer que é até comum (ou naturalizado pela cultura dos alunos) de associar os alunos negros a macacos ou outras ofensas de cunho pejorativo. As religiões de matrizes africanas também são pouco toleradas, sendo elas usadas como adjetivo difamatório por muitos alunos. (Depoimento 2).

O combate a esses preconceitos (raciais, religiosos e sociais), perpassa por algumas estratégias como explicar e orientar os estudantes no momento que ocorreu o fato e, 
posteriormente, desenvolver atividades utilizando músicas, clipes e slides que mostrem aos alunos como lidar e aceitar as diferenças, deixando sempre nítido que estamos inseridos no mesmo contexto social.

Uma das atividades realizadas, por exemplo, foi a utilização do clipe "Black to White", de Michael Jackson, no qual a música tinha uma mensagem de promover a unidade racial. Em seguida ocorreu um debate que levou os alunos a refletirem sobre os diferentes tipos de culturas, sociedades e cultos religiosos.

Outra atividade realizada foi a entitulada "Tempo e Corpo", que teve o objetivo de fazer com que esses alunos compreendessem a dimensão do tempo histórico, a fim de que entendam o processo de transformação social e compreendam as sociedades em suas complexidades. Ou seja: o objetivo principal se volta para a reflexão acerca das diferenças que se firmam no tempo e nos diferentes espaços de convívio. Foi apresentado aos alunos um vídeo que continha imagens de manifestações culturais de diferentes épocas e sociedades, além de trechos de documentários/filmes sobre conflitos e guerras geradas pelo preconceito e intolerância. O vídeo, portanto, mostrou o quanto as sociedades podem se modificar ao longo do tempo, de modo que os alunos conseguissem observar que as diferenças existem e que fazem parte de um processo histórico. Ao final do vídeo, pedimos que fosse feita uma roda de conversa com os alunos, onde eles fizessem a associação dos significados dos conceitos de discriminação, racismo, homofobia a alguma coisa que viram no vídeo apresentado. Durante a roda de conversa, nos deparamos com uma situação imprevista que nos deu o gancho para iniciarmos o debate: dois alunos, com distintas acerca da criação do universo, começaram a impor um ao outro suas opiniões e suas supostas verdades. A partir daí, começamos uma conversa na qual buscamos esclarecer a importância de aceitação e coexistência. 


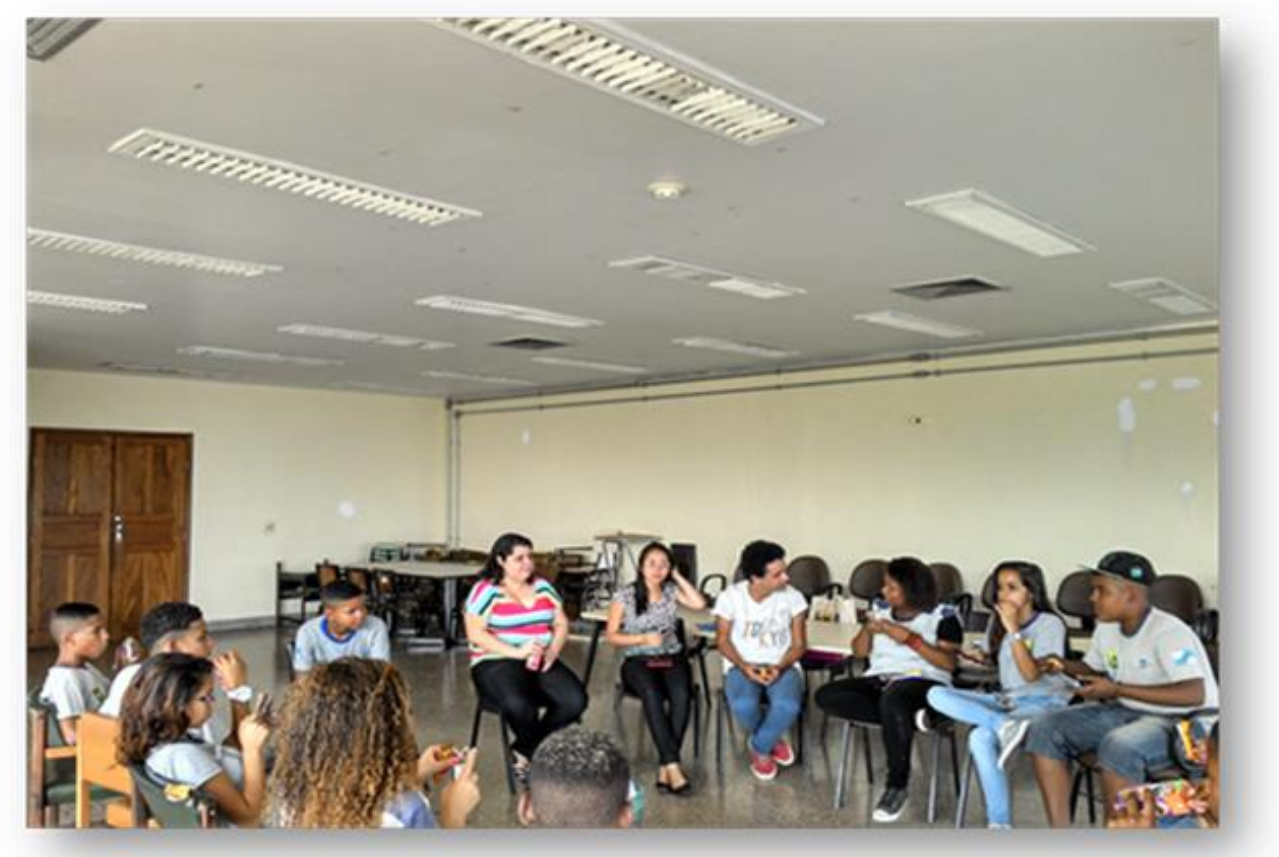

Figura 2 - Professora Supervisora, bolsistas do Projeto PIBID História da Faculdade de Formação de Professores da Universidade do Estado do Rio de Janeiro com os alunos da turma 603. Foto tirada dia 13 de outubro de 2014 durante a atividade "Tempo e Corpo".

Obviamente, um simples vídeo não é capaz de mudar a forma desses alunos pensarem sobre esses assuntos, geralmente considerados verdadeiros tabus. Porém, o trabalho sistemático e o debate com os alunos fazem com que eles consigam acompanhar a discussão histórica de forma a não hierarquizar e atribuir valores dicotômicos para as diferentes sociedades.

Dessa forma, compreendemos que um debate mais amplo sobre a tolerância e o combate ao preconceito pode nos levar a uma série de atividades mais aprofundadas sobre a questão étnico-racial, com o intuito de desconstruir essa visão eurocêntrica que os alunos estão acostumados a seguir e, assim, para além de tolerar, aceitar e respeitar as diferentes culturas e povos.

\section{Considerações finais}

Com este trabalho, concluímos que a Lei 10.639/03 fomenta o debate acerca da diversidade dentro do currículo de História, além a apresentar a necessidade desse debate, já que, por um lado, possibilita a elaboração de um currículo mais atraente para o aluno e, por 
outro, possibilita a criação de um ensino de História que eduque para a diversidade. Porém, essa lei não é cumprida como deveria.

Através dos relatos dos bolsistas, percebemos que o racismo está presente em toda a estrutura da escola, não tendo pontos específicos em que se é praticado, ou melhor, essas práticas aparecem com uma maior frequência sempre que se foge da uma realidade européia/ocidental, como diz José Ricardo Oriá Fernandes (2005), e isso acaba revelando a face oculta do racismo.

Em relação às atividades aplicadas, é importante salientar que essas foram o ponto de partida para ampliação do nosso debate com os alunos, contudo é necessário pensar outros caminhos; caminhos que possibilitem a criação de uma educação socialmente referenciada e que ensine para a diversidade.

\section{REFERÊNCIAS}

ALBERTI, Verena. Algumas estratégias para o ensino de história e cultura Afro-Brasileira In: PEREIRA, Amílcar Araújo; MONTEIRO, Ana Maria. (Orgs). Ensino de história e culturas Afro Brasileira e Indígenas. Rio de Janeiro: Pallas, 2013 p.27-55.

CANDAU, V. M.; MOREIRA, A. F. B. Currículo, Conhecimento e Cultura. In: BEAUCHAMP, Jeanete; PAGEL, Sandra Denise; NASCIMENTO, Aricélia Ribeiro do. (Orgs). Indagações sobre currículo: currículo, conhecimento e cultura. Brasília: Ministério da Educação, Secretaria de Educação Básica, 2007.

FERNANDES, J. R. O. Ensino de História e Diversidade Cultural: Desafios e Possibilidades. Cad. Cedes, Campinas, vol. 25, n. 67, p. 378-388, set./dez. 2005 Disponível em:

<http://www.cedes.unicamp.br>. Acesso em 14 out. 2014.

GUIMARÃES, Selva. A Nova LDB, os PCN's e o Ensino de História. In: GUIMARÃES, Selva. Didática e prática de ensino de história: Experiência, reflexões e aprendizados. São Paulo: Papirus, 2003. p. 29-38.

GOODSON, I. F. Currículo: Teoria e História. 8. Ed. - Petrópolis, RJ: Editora Vozes, 2008.

KELLY, A. V. O que é o currículo? In: KELLY, A. V. O currículo. Teoria e Prática. (1981). São Paulo: Harbra. p. 3-7.

MACEDO, E. Currículo: Política, Cultura e Poder. In: MACEDO, E. Currículo sem Fronteiras, v. 6, n. 2, pp.98-113, jul./dez. 2006. 
PAULA, G. J. Q. de. O Ensino de História e a Diversidade Cultural Brasileira: Maneiras e Possibilidades. Ágora, Santa Cruz do Sul, v. 15, n. 1, p. 137 a 147, jan./jun. 2009. Disponível em: <http://online.unisc.br/seer/index.php/agora/arti cle/view/1790/1338>. Acesso em 14 out. 2014.

SANTOS, Lorene dos. Ensino de história e culturas afro-brasileiras e índigenas: dilemas e desafios da recepção à lei 10.639/03. In: PEREIRA, Amilcar Araujo; MONTEIRO, Ana Maria. (Orgs). Ensino de história e culturas afro-brasileiras e indigenas. Rio de Janeiro: Pallas, 2013. p.57-84.

SILVA, T. T. Documentos de identidade: uma introdução às teorias do currículo. Belo Horizonte: Autêntica, 1999.

\footnotetext{
${ }^{\text {i }}$ Licencianda em História pela Faculdade de Formação de Professores da Universidade do Estado do Rio de Janeiro (FFP-UERJ). Atualmente é bolsista do Programa Institucional de Bolsas de Iniciação à Docência (PIBID), pelo Subprojeto História, intitulado "As estratégias didáticas na aprendizagem do conhecimento histórico escolar", sob a coordenação da Professora Doutora Maria Aparecida da Silva Cabral, e desenvolve pesquisa nos temas Ensino de História; Racismo e Antirracismo.

ii Acho importante ressaltar que, ao utilizar o termo intolerância, não defendo que as pessoas apenas tolerem as outras, mas entendo que esse é o primeiro passo para que criemos uma sociedade igualitária.

iii É oferecido pela Secretária de Educação do Estado do Rio de Janeiro (Seeduc - RJ) desde 2012 e tem como objetivo oferecer aos estudantes da rede estadual uma base comum que leve à construção do conhecimento e da cidadania, através do processo de ensino-aprendizagem

iv Perfil dos Adolescentes e Jovens Fluminenses foi um perfil criado pelos bolsistas do Subprojeto História da Faculdade de Formação de Professores da Universidade do Estado do Rio de Janeiro. Foi formulado por um questionário respondido pelos alunos e tabulado em seguida. O objetivo desse perfil é que tenhamos registrado o perfil dos jovens que trabalhamos no projeto.

${ }^{v}$ Depoimento adquirido em questionário aberto com bolsista do PIBID História FFP-UERJ.
} 